\title{
Investigation of PCBM Concentration on the Performance of Small Organic Solar Cell
}

\author{
Yasser A. M. Ismail, ${ }^{1}$ T. Soga, ${ }^{2}$ and T. Jimbo ${ }^{2}$ \\ ${ }^{1}$ Department of Physics, Faculty of Science, Al-Azhar University, Assiut 71121, Egypt \\ ${ }^{2}$ Department of Frontier Materials, Nagoya Institute of Technology, Nagoya 466-8555, Japan
}

Correspondence should be addressed to Yasser A. M. Ismail, yasser_ami@yahoo.com

Received 10 April 2012; Accepted 15 July 2012

Academic Editors: F. E. Little and P. Poggi

Copyright (C) 2012 Yasser A. M. Ismail et al. This is an open access article distributed under the Creative Commons Attribution License, which permits unrestricted use, distribution, and reproduction in any medium, provided the original work is properly cited.

\begin{abstract}
We have fabricated bulk heterojunction organic solar cells using coumarin 6 (C6) as a small organic dye, for light harvesting and electron donating, with fullerene derivative $[6,6]$-phenyl- $\mathrm{C}_{61}$ butyric acid methyl ester (PCBM), acting as an electron acceptor, by spin-coating technique of the blend solutions. We have studied effect of PCBM concentration on photocurrent and performance parameters of the solar cells. We found that the optical absorption of the dye increased with increasing its concentration in the active layer blends. The higher concentrations of PCBM in active layer enhanced the photocurrent of the solar cells, as a result of improving charge carrier separation and electron transport in solar cell active layer. The improved charge carrier separation between C6, as a donor, and PCBM, as an acceptor, was indicated through the formation of bulk heterojunction by blending C6 with PCBM. The formation of C6:PCBM bulk heterojunction blend was confirmed through the symbatic behavior of the corresponding solar cell and, also, through the homogeneity and smoothing in the atomic force microscopy images of the C6:PCBM blend films. For the same reasons, the performance parameters of the C6:PCBM solar cell improved by modification of the PCBM concentration in the solar cell active layer.
\end{abstract}

\section{Introduction}

Organic solar cells are an emerging photovoltaic technology that is inexpensive and easy to manufacture, despite low efficiency and stability [1]. Organic solar cells have attracted a great deal of attention in view of their potential for the fabrication of large-area and flexible photovoltaic devices [2]. Bulk heterojunction (BHJ) organic solar cells are composed of interpenetrating networks of p-type semiconducting donor material and n-type semiconducting acceptor material in a solution, which can be deposited by a printing process, and are thus compatible with low-cost role-to-role fabrication technology. The BHJ blends provide an approach for high efficiency solar cells, since high interfacial area within $\mathrm{BHJ}$ material tends to large number of generated charge carriers and photocurrent in the solar cells. The BHJ solar cells performed with power conversion efficiency from solar light into electrical energy of up to about $6.8 \%$ [3].
For increasing knowledge of materials science for photovoltaic applications, new $\mathrm{BHJ}$ systems should be studied. For significant improvement in organic solar cell efficiency, new donor/acceptor combinations may be required to recognize and identify the photovoltaic properties of materials used in solar cells. To construct a BHJ blend using low molecular weight compounds such as coumarin dyes, it is better first to show the advantages of this kind of organic dyes. The coumarin dyes have a pronounced light harvesting, and they have been used as light absorbers (third material) for photovoltaic devices [4]. They have been extensively used as photosensitizers in Grätzel-type dye-sensitized solar cells [5, 6], like many other organic dyes $[7,8]$. The coumarin dyes have been used as dopants in polymer light emitting diodes (LEDs) $[9,10]$, and as luminescent solar concentrators applied upon solar cells $[11,12]$. Novel iminocoumarin dyes having carboxyl and hydroxyl anchoring groups onto the dyes skeletons have been designed and synthesized by Kandavelu et al. 
[13] for the application of dye-sensitized nanocrystalline $\mathrm{TiO}_{2}$ solar cells. Fullerene- $\left(\mathrm{C}_{60^{-}}\right)$based donor-acceptor polyads were synthesized by Brites et al. [14], in which $\mathrm{C}_{60}$ as an acceptor material was covalently linked to some of coumarin dyes as donor materials, towards practical applications such as photovoltaic devices for solar energy conversion. When selecting donor and acceptor material pair for photovoltaic application, one needs to consider their energy levels. The highest occupied molecular orbital (HOMO) and lowest unoccupied molecular orbital (LUMO) of the material pair need to match in such a way that exciton dissociation (charge separation) will be favored at the interface of the two materials. The conjugated coumarin 6 (C6) dye in combination with the fullerene derivative $[6,6]-$ phenyl- $\mathrm{C}_{61}$ butyric acid methyl ester (PCBM) shows a thermodynamically suitable charge separation at the interface, after light absorption by the sensitized C6 dye. The charge separation in the C6:PCBM combination can occur as a result of decreasing the electron affinity (higher LUMO level) and ionization potential (higher HOMO level) of C6, as a donor, in comparison with those of PCBM, as an acceptor, as shown in Figure 1 from $[15,16]$. Therefore, the interfacial electric field of the C6:PCBM binary drives charge separation, and the generated electrons are transported by PCBM into the cathode, while the generated holes are transported by $\mathrm{C} 6$ into the anode. Hence, the $\mathrm{C} 6$ dye can be used in $\mathrm{BHJ}$ solar cells for light harvesting and electron donating in the combination with PCBM molecules. Although organic dyes have been extensively used in dye-sensitized solar cells and as a third material for light harvesting in another type of organic solar cell, there are few papers on organic BHJ solar cells based on organic dyes as donor materials. In particular, as far as we know, we are the first researchers who utilize the C6 dye as a donor material in organic BHJ solar cells.

The effect of the C6:PCBM composition on the solar cell performance is the second goal in this work, while the construction of organic solar cells using C6 dye as a light harvester and donor material is the first goal. Besides the absorption of light by the dye and, consequently, creation of photogenerated charge carriers, the other requirement for solar cell efficiency is the ability to transport these charge carriers into respective electrodes. The importance of PCBM molecules of the solar cell performance obviously appeared in the polymer:PCBM blends, which were used in the BHJs. In these systems, the hole and electron mobilities depend on the content of PCBM in the blends. The increase in PCBM content increases the electron mobility, while the hole mobility decreases only slightly [17]. The PCBM clusters in the solar cell active layer efficiently transport the photogenerated mobile electrons by means of percolated pathways to the respective electrode.

In this work, we construct indium-tin-oxide (ITO)/poly (3,4-ethylene dioxythiophene)-blend-poly(styrene sulfonate) (PEDOT:PSS)/C6:PCBM/Al solar cells with variation of the PCBM weight percentage (wt \%) in the active layer blends and investigate the effect of C6:PCBM composition on the photocurrent and solar cell performance. The optical absorption spectroscopy, photocurrent spectroscopy, and current density-voltage $(J / V)$ characteristics under AM1.5

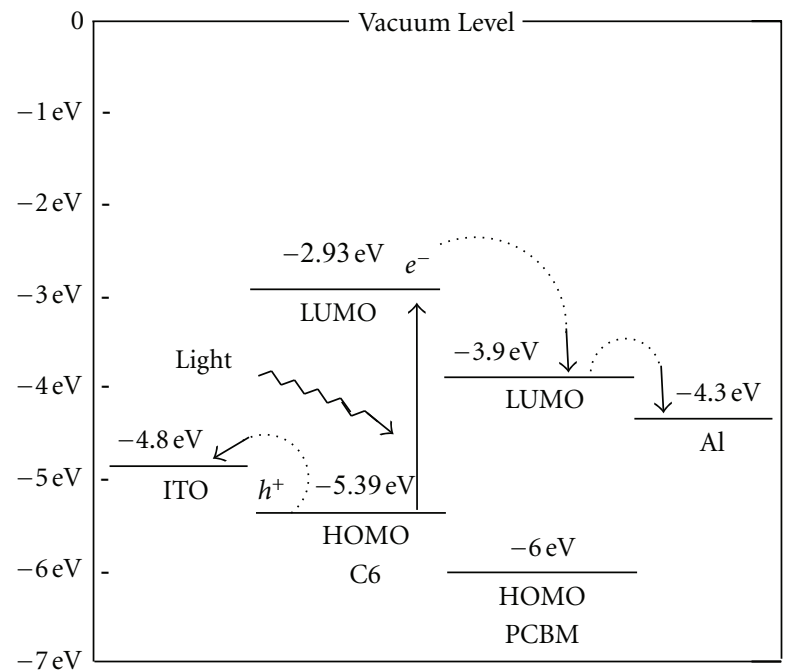

FIGURE 1: Energy-level diagram of PCBM (from [15]) and C6 dye (from [16]) relative to vacuum.

white light illumination with an intensity of $100 \mathrm{~mW} / \mathrm{cm}^{2}$ are investigated for the solar cells with varying the composition of the C6:PCBM blends.

\section{Experimental Procedure}

2.1. Materials and Solutions. The C6 (3-(2-benzothiazolyl)7-(diethylamino)coumarin) conjugated laser dye and $[6,6]-$ phenyl- $\mathrm{C}_{61}$ butyric acid methyl ester (PCBM) were purchased from Sigma-Aldrich and used without further purification. The blend solutions of C6:PCBM combination were prepared by dissolving different weight percentages of the two components (as 100:0, 80:20,60:40, 40:60, and $20: 80$ wt \%) in 1,2-dichlorobenzene (from Sigma-Aldrich) with a concentration of $20 \mathrm{mg} / \mathrm{mL}$. The solutions were vigorously stirred for more than $24 \mathrm{~h}$ at room temperature under nitrogen atmosphere in a glove box to maximize mixing while avoiding touching the vial cap.

2.2. Film and Device Fabrication. For optical absorption measurement, the pristine C6 and C6:PCBM blend films were prepared by spin-coating the solutions onto clean microglass substrates. The film preparation and thermal annealing conditions were kept the same as those of the corresponding device for accurate comparison. For solar cell fabrication, the ITO-glass substrates $(\sim 10 \Omega / \square)$ were sequentially cleaned in an ultrasonic bath using acetone (twice) and methanol (once), rinsed with deionized water, and finally dried in flowing nitrogen. To increase the work function of the ITO electrode and to improve the electrical connection between the ITO electrode and the organic active layer, a layer of PEDOT:PSS was spin-coated (at $2500 \mathrm{rpm}$ ) onto ITO-glass substrate in air and dried using a digitally controlled hotplate at $100^{\circ} \mathrm{C}$ for $10 \mathrm{~min}$ under nitrogen atmosphere in a glove box. On top of the insoluble 
PEDOT:PSS layer, the C6:PCBM blend solution was spincoated (at $2500 \mathrm{rpm}$ ) and dried, to remove the residual solvent, at $100^{\circ} \mathrm{C}$ for $10 \mathrm{~min}$ under nitrogen atmosphere. An approximately $100 \mathrm{~nm}$ thick Al electrode was thermally deposited onto the active layer using a vacuum deposition system at a pressure of about $3 \times 10^{-4} \mathrm{~Pa}$ through a shadow mask to obtain 25 identical cells on one device with an active area of $3 \times 3 \mathrm{~mm}^{2}$. Finally, the complete solar cells were annealed at $140^{\circ} \mathrm{C}$ for $4 \mathrm{~min}$ in a nitrogen atmosphere. The use of nitrogen atmosphere is for suppressing the formation of carbonyl defects during the thermal treatment that reduces the conjugation length and thus lowers the electrical conductivity when oxidized. The complete organic solar cells, with the structure as shown in Figure 2, were stored in the dark under suitable pressure until measurement.

2.3. Measurements. The optical absorption spectroscopy of pristine $\mathrm{C6}$ and C6:PCBM blend films was carried out using a JASCO V-570 ultraviolet/visible/near-infrared (UV/Vis/ NIR) spectrophotometer with incident light towards the coated side of the films. The external quantum efficiency measurement was performed for devices using a halogen lamp and a monochromator. The $J / V$ characteristics of the devices under white light illumination were determined using standard solar irradiation of $100 \mathrm{~mW} / \mathrm{cm}^{2}$ (AM1.5) with a JASCO CEP-25BX spectrophotometer $J / V$ measurement setup with a xenon lamp as the light source and a computer-controlled voltage-current source meter (Keithley $238)$ at $25^{\circ} \mathrm{C}$ under nitrogen atmosphere. The $J / V$ characteristics were determined for many cells in one device, and we considered the performance parameters of the best solar cell in that device. All measurements were performed soon after preparation of the devices to avoid any change in the photoelectric properties caused by aging. The external quantum efficiency and performance parameter values in this work did not consider the device degradation caused by light and air during the transferring the devices from glove box, after preparation, to $J / V$ measurement apparatus, which distances around $30 \mathrm{~m}$ far from the glove box.

\section{Results and Discussion}

3.1. Optical Properties of Blend Films. The importance of C6 dye as a light harvester in solar cell applications was previously discussed by Jiang et al. [4]. The investigated active layer was composed of $\mathrm{N}, \mathrm{N}^{\prime}$-bis(2,5-di-tert-butylphenyl)-3,4,9,10-perylenedicarboximide (PDCBI) as an electron acceptor and $\mathrm{N}, \mathrm{N}^{\prime}$-bis(3-methylphenyl)-N, $\mathrm{N}^{\prime}$ diphenylbenzidine (TPD) as an electron donor. The incorporation of C6 dye into PDCBI:TPD combination efficiently enhanced the light absorption and photocurrent of the solar cell.

Figure 3 shows the optical absorbance of pristine C6 and C6:PCBM blend films with varying the PCBM wt \% in the wavelength range of $200-700 \mathrm{~nm}$. In this figure, the pristine C6 dye, which is used as a sensitizer for light harvesting, gives an eminent absorption peak at a wavelength of approximately $426 \mathrm{~nm}$ in the range of $350-550 \mathrm{~nm}$. By

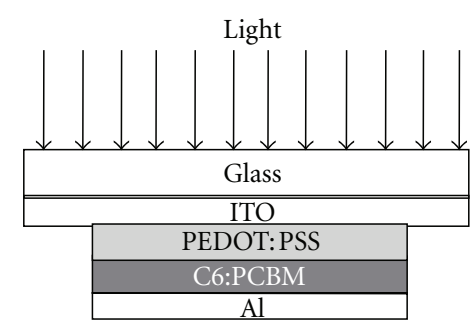

(a)<smiles>CCN(CC)c1ccc2cc(-c3nc4ccccc4s3)c(=O)oc2c1</smiles>

(b)

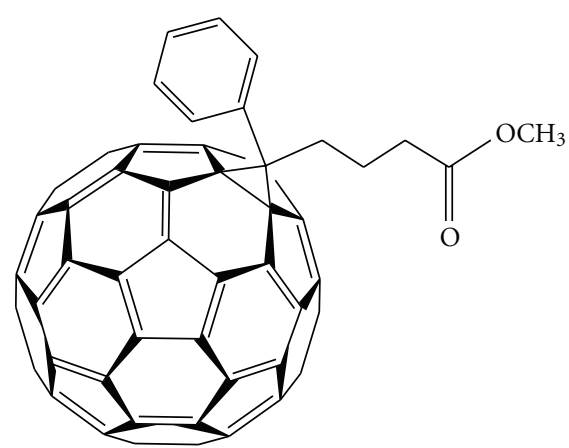

(c)

FIgURE 2: (a) Cross-sectional view of organic photovoltaic device and chemical structure of (b) C6 and (c) PCBM.

increasing PCBM concentration, the C6 absorption peak in the blend films tends to be the following:

(1) gradually decrease in the height in comparison with the PCBM absorption peak, which increases with increasing PCBM wt \% in the blends,

(2) red shift to a wavelength of $432 \mathrm{~nm}$ with adding $20 \%$ of PCBM into the blends, while the adding 60 or $80 \%$ of PCBM tends to red-shift the C6 absorption peak to $454 \mathrm{~nm}$.

The observed decrease in the dye absorption peak in Figure 3 is as a result of decreasing dye concentration and, in the same time, increasing the PCBM concentration in the blends. The red shift in the C6 absorption peak after blending with PCBM molecules (at different concentrations) may be attributed to the formation of a charge transfer complex (CTC) in the C6:PCBM blend films as a result of a significant interaction between conjugated C6 dye and PCBM molecules in the ground state. In general, the red shift in the absorption spectrum, as an indication of the formation of a CTC in the blends, has been frequently stated in the literature [18-20]. Moreover, Figure 3 shows the 


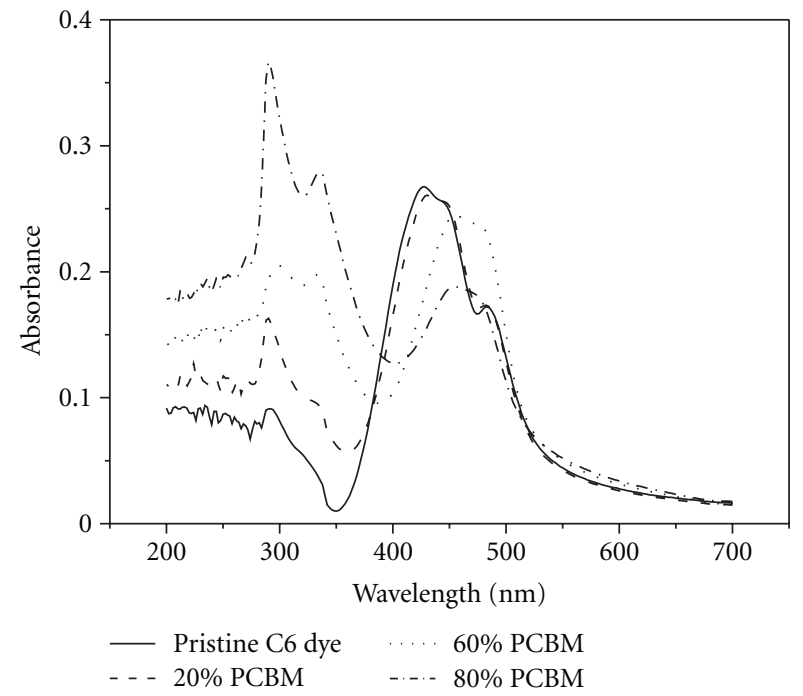

Figure 3: Optical absorbance of pristine C6 dye and C6:PCBM blend films with varying PCBM wt \%.

contribution of PCBM molecules in the absorption of the C6:PCBM blend films. The contribution of PCBM molecules in the optical absorption gradually increases by gradual increase in PCBM wt \% at a wavelength of approximately $332 \mathrm{~nm}$. The adding of $80 \%$ of PCBM into active layer blend reduces the absorption of the sensitized dye. Therefore, the excepted photocurrent in this case will be smaller than that of solar cells having the lower PCBM concentration. This is because adding a large amount of the PCBM molecules into a small amount of the dye in the active layer blend reduces the density of the C6 aggregates, which are the responsible for photosensitization and absorption in the visible region of the solar spectrum.

3.2. External Photocurrent Quantum Efficiency Spectra. The external quantum efficiency (EQE) is defined as the ratio of the number of charges extracted out of the device to the number of incident photons. The EQE spectra of the ITO/ PEDOT:PSS/C6:PCBM/Al solar cells with increasing PCBM concentration in the blends are shown in Figure 4 in the wavelength range from 300 to $700 \mathrm{~nm}$. By increasing the wt $\%$ of the PCBM in the C6:PCBM blend, the EQE maximum peak relating to the contribution of the $\mathrm{C} 6$ in the photocurrent increases. This increase begins from $1.3 \%$ at $450 \mathrm{~nm}$ of the cell that has $20 \%$ of the PCBM to $7.73 \%$ at $475 \mathrm{~nm}$ of the cell that has $40 \%$ of the PCBM and, finally, reaches $12.39 \%$ at $475 \mathrm{~nm}$ of the cell that has $60 \%$ of the PCBM in the blend, where the C6 dye absorbs light at about $454 \mathrm{~nm}$ as shown in Figure 3.

As a result of light absorption by C6 dye, the excitons generate and diffuse into C6:PCBM interfaces. At the interfaces, the excitons dissociate into free electrons and holes, as a result of the internal electric field resulted from the difference in electron affinity and ionization potential between C6, as a donor, and PCBM, as an acceptor, in the BHJ active layer. The generated charge carriers at the interfaces in the
C6:PCBM blend are transported into respective electrodes. The electrons are transferred by PCBM towards the $\mathrm{Al}$ electrode under the influence of the electrode work function, and the holes are transferred by $\mathrm{C} 6$ under the influence of the work function of ITO/PEDOT:PSS. Then, the photocurrent is produced from the device.

$\mathrm{A} \mathrm{BHJ}$ is usually obtained by relying on the phase separation (on the nanometer scale) of donor and acceptor materials in a mixed layer, where insufficient phase separation often compromises the device performance owing to carrier recombination and poor charge transport [21]. In general, and as a result of phase separation on the nanometer scale occurring in the active layer blend, the donor/acceptor interfaces (photoactive p-n heterojunction sites) spread within the entire volume of the $\mathrm{BHJ}$ composite layer. Therefore, the limitations of exciton migration and charge separation are overcome. Moreover, in the BHJ, both materials (donor and acceptor) have percolating paths to their respective electrode to ensure efficient charge transport and collection. Therefore, the formation of a $\mathrm{BHJ}$ as a solar cell active layer improves the generated photocurrent from the solar cell. The formation of a BHJ by blending C6 dye as a donor material with PCBM as an acceptor material and the resulting efficient charge separation and transport throughout the C6:PCBM blend are verified through the symbatic behavior of the solar cell. The symbatic behavior of an active layer blend indicates matching in the wavelength range at which both the EQE and absorption spectra of the active layer are observed. The symbatic behavior of the C6:PCBM solar cell (40:60 wt \% as an example) appears in the inset of Figure 4. For more verification, we investigate the interpenetrating networks of the C6 dye with PCBM molecules in a BHJ blend by Atomic Force Microscopy technique (AFM). The formation of BHJ by blending C6 dye as a donor material with PCBM as an acceptor material and the resulting possible efficient charge separation throughout the C6:PCBM blend are verified through homogeneity and smoothing in the AFM images, as shown in Figure 5. In this figure, the phase separation on the nanometer scale obviously appears for the C6 donor (as dark domains) and PCBM acceptor (as bright domains) in the C6:PCBM blend film.

The increase in the photocurrent with increasing PCBM concentration in the blends, as observed in Figure 4, is attributed to two mean reasons. First, the increase in PCBM wt $\%$ increases the exciton dissociation at the interfaces between $\mathrm{C} 6$ and PCBM in the BHJ blend. By increasing PCBM wt \% in the blends, the nanoscale phase segregation increases (as observed in Figure 5), and, therefore, the interfacial area between donor and acceptor molecules (photoactive p-n heterojunction sites) increases. The increase in the number of photoactive $p-n$ heterojunction sites through a more even distribution of fullerene clusters inside the blends tends to enhance the charge separation and photocurrent, as reported previously for P3HT:PCBM solar cells [22, 23]. Second, the increase in PCBM wt \% in the solar cell active layer increases the electron transport towards $\mathrm{Al}$ electrode and, therefore, increases the photocurrent. As previously reported, the most efficient devices had a large fullerene content of up to $80 \%$ by weight [24-27]. Field-effect mobility measurements for 


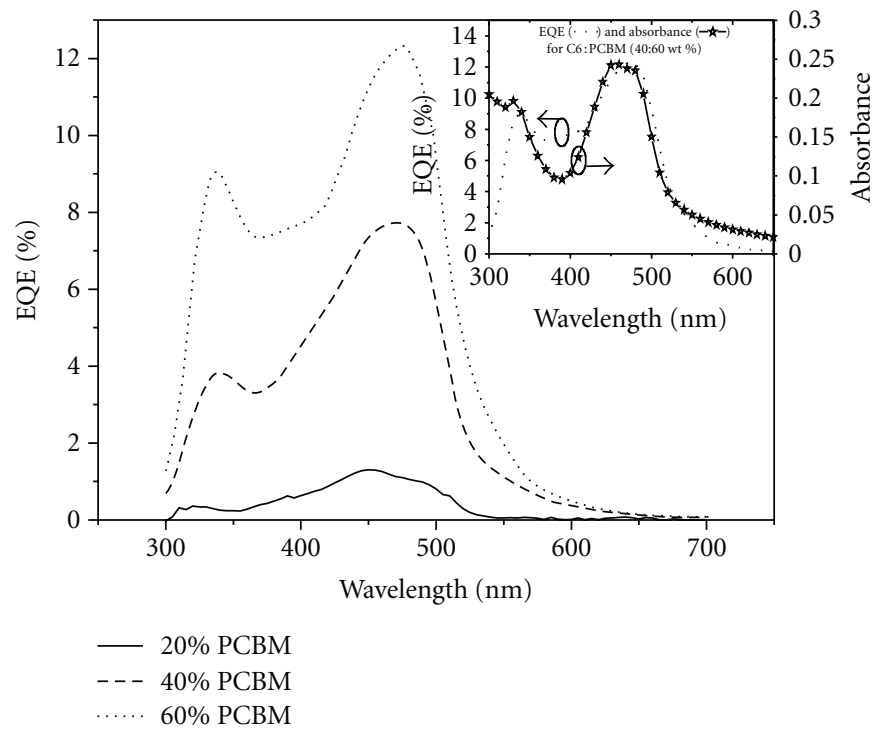

FIGURE 4: EQE spectra of the ITO/PEDOT:PSS/C6:PCBM/Al devices with increasing PCBM wt \%. The inset shows the symbatic behavior for C6:PCBM ( $40: 60$ wt \%) blend as an example.

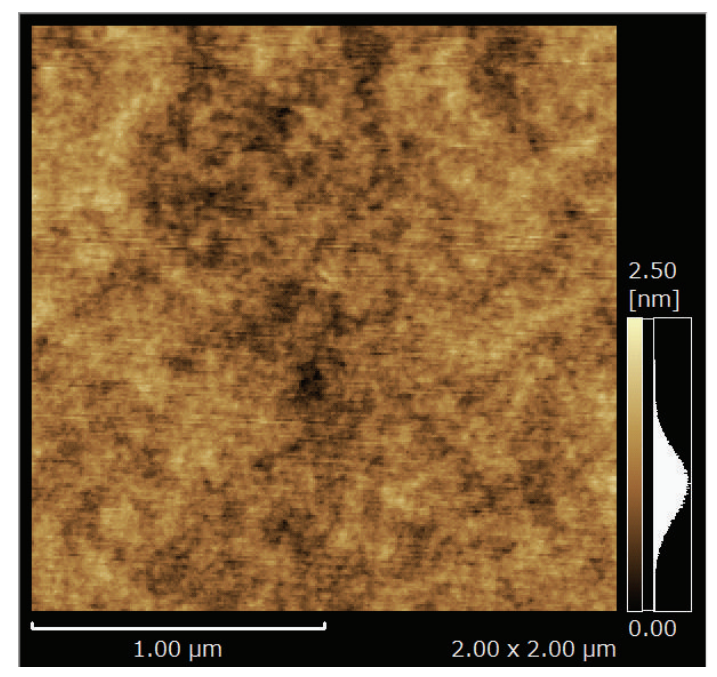

(a)

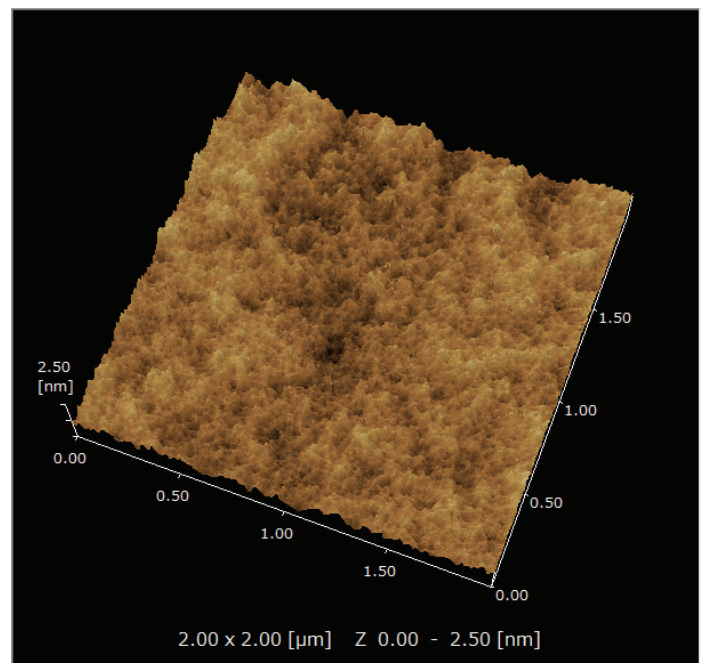

(b)

Figure 5: AFM images of C6:PCBM blend film (40:60 wt \%) spin-coated onto microglass substrate.

different blends of MEH-PPV and PCBM showed an increase in electron mobility upon an increase in the fullerene content [28]. Similar trend has been found for MDMO-PPV:PCBM system [29]. Therefore, the high PCBM load is needed for an efficient electron transport, indicating that a minimum grain size of the PCBM acceptor phase may be necessary to ensure percolated pathways for the electrons [30]. The effect of blending ratio of P3HT as a donor and PCBM as an acceptor on the solar cell performance was discussed by Nakamura et al. [17]. The best performance of the P3HT:PCBM combination at a specific blending ratio was attributed to two factors. One was the increase in photoactive $\mathrm{p}-\mathrm{n}$ heterojunction sites by blending the donor and acceptor, resulting in an increase in the photocurrent. Second was that enough magnitude of the charge carrier mobility even in the blended solid was secured. It is known that the PCBM can contribute to a large extent to the photocurrent of the polymer:PCBM solar cells, as discussed by Hoppe et al. [31]. Indeed, the EQE spectrum of the investigated solar cells in Figure 4 shows the contribution of PCBM to the photocurrent at a wavelength of approximately $340 \mathrm{~nm}$, which absorbs light at about $332 \mathrm{~nm}$, as shown in Figure 3.

3.3. Device Performance under White Light Illumination. We have measured $J / V$ characteristics of the ITO/PEDOT:PSS/ C6:PCBM/Al devices under AM1.5 white light illumination with an intensity of $100 \mathrm{~mW} / \mathrm{cm}^{2}$ as a function of PCBM 


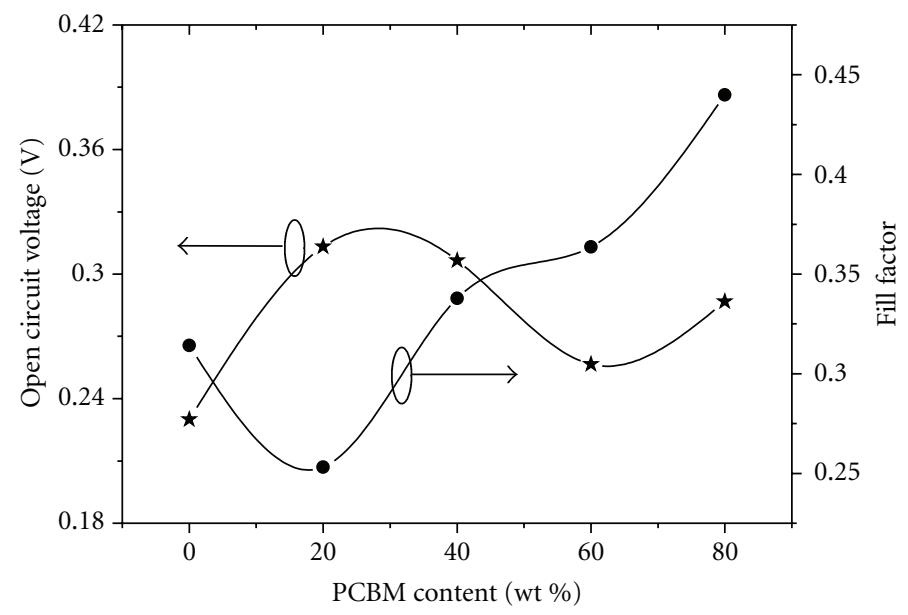

FIgure 6: Variation of $V_{\mathrm{OC}}(\star)$ and FF $(\bullet)$ with increasing PCBM wt \% in the ITO/PEDOT:PSS/C6:PCBM/Al devices.

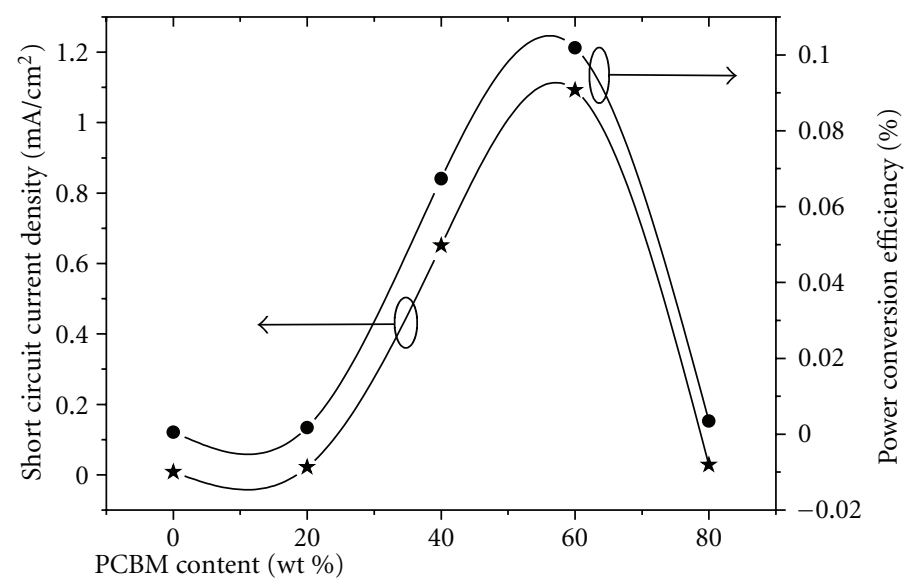

FIGURE 7: Variation of $J_{\mathrm{SC}}(\star)$ and PCE $(\bullet)$ with increasing PCBM wt \% in the ITO/PEDOT:PSS/C6:PCBM/Al devices.

wt $\%$ in the solar cell active layer. From the analysis of the $J / V$ characteristics, we have obtained the photovoltaic performance parameters, that is, open circuit voltage $\left(V_{\mathrm{OC}}\right)$, short circuit current density $\left(J_{S C}\right)$, fill factor $(\mathrm{FF})$, and power conversion efficiency (PCE), of the investigated devices. Figures 6 and 7 show the variation of these parameters with increasing PCBM wt \% in the solar cell active layer. Figure 6 shows increase in $V_{\mathrm{OC}}$ from 0.23 to $0.31 \mathrm{~V}$ after adding $20 \%$ of PCBM into active layer, and after that, the $V_{\text {OC }}$ value alternates closely around $0.3 \mathrm{~V}$ with increasing PCBM concentration until 80\%. The FF, in Figure 6, increases continuously up to 0.44 with increasing PCBM concentration from $20 \%$ to $80 \%$. Figure 7 shows enhancement in the $J_{S C}$ and PCE with increasing PCBM wt \% in the active layer. The $J_{\text {SC }}$ increases up to $1.1 \mathrm{~mA} / \mathrm{cm}^{2}$ with increasing PCBM wt \% up to $60 \%$, and after that, $J_{\mathrm{SC}}$ decreases to $0.03 \mathrm{~mA} / \mathrm{cm}^{2}$ at $80 \%$ of PCBM. Consequently, the PCE increases up to $0.1 \%$ at $60 \%$ of PCBM and, after that, decreases to become $0.004 \%$ at $80 \%$ of PCBM.

The variation of $V_{\mathrm{OC}}$ in Figure 6 maybe does not attribute to variation of PCBM concentration in the mixture of $\mathrm{BHJ}$ layer. Studies on MDMO-PPV:PCBM devices showed that the $V_{\mathrm{OC}}$ was composition independent for PCBM contents above about $10 \%$ by weight [21]. For organic BHJ materials, the general perception is that $V_{\mathrm{OC}}$ is determined by the energy difference between the HOMO of the donor and the LUMO of the acceptor [15]. The largest value of $V_{O C}$ in Figure 6 is $0.31 \mathrm{~V}$, which may be small in comparison with the difference between the HOMO of the donor and the LUMO of the acceptor, with assumption that the results of cyclic voltammetry from $[15,16]$ are accurate for the materials. This can be explained by the fact that the electrochemical studies are carried out for dissolved molecules in solution, while tightly packed $\pi-\pi$ aggregates are formed in the solid state; thus, it is assumed that the redox potentials of individual molecules in solution do not properly reflect the energetic situation in a solid material, and hence in the actual device [32]. This leads to an alteration of the frontier orbital energies of molecules in C6:PCBM composite compared to those of isolated molecular species. The continuous increase in FF (up to 0.44 ) by increasing PCBM content (up to $80 \%$ ), as shown in Figure 6, is a result of continuous lowering in 
the series resistance of the active layer with increasing PCBM concentration, which is responsible for the electron transfer in the blends. In the BHJ solar cells, the FF relates to the series resistance of the active layer, which reduces as the charge mobility increases [33].

The increase in the $J_{\mathrm{SC}}$ and, consequently, PCE with increasing PCBM wt $\%$ up to $60 \%$ may be attributed to two factors, as discussed before for EQE. First, because of increase in the photoactive $\mathrm{p}-\mathrm{n}$ heterojunction sites by blending C6 donor with PCBM acceptor. Second, because of increase in charge carrier transfer throughout the PCBM rich domains in the solar cell active layer. The transport of photogenerated charges through the active layer seems to improve with the increasing PCBM content [32]. The PCBM rich domains in the blends may assist charge collection in the high PCBM content blends, owing to the high electron mobility in the PCBM [34]. There is another factor affecting the $J_{\mathrm{SC}}$ characteristics of the $\mathrm{BHJ}$ solar cells, that is, the dye concentration in the blends. At $60 \%$ of the PCBM in the active layer, the $J_{\mathrm{SC}}$ is produced in the corresponding solar cell with the highest value. This is because the concentration of the dye in the blends is still significant to absorb large number of light photons and to generate enough numbers of charge carriers, which are transported efficiently through percolated pathways in the solar cell active layer. However, the solar cell active layer at low concentration of the dye (at $80 \%$ of PCBM) cannot absorb significant numbers of light photons to produce high value of $J_{\mathrm{SC}}$, even with high charge carrier transport at high concentration of PCBM. The significant increase in FF (0.44; Figure 6) at high concentration of PCBM (80\%) and low concentration of C6 dye can be taken as an indication for this assumption.

At $80 \%$ of PCBM, the mobility of holes in the active'layer reduces, as a result of reduction in dye concentration in the active layer blends, and, therefore, the photovoltaic performance reduces. The same discussion is argued by Geens et al. [35] in the case of using bulk donor/acceptor heterojunctions based on a blend of poly (2-methoxy-5-(39,79dimethyloctyloxy)-1,4-phenylene-vinylene) (OC1C10-PPV) and PCBM. According to the FF behavior in Figure 6, it is expected that the solar cell with $100 \%$ of PCBM will gain higher electron mobility, because the electron transport network formed by PCBM molecules will spread across the whole solar cell film. However, in the same time and according to $J_{\mathrm{SC}}$ results from Figure 7 , the photocurrent will not be generated considerably in the solar cell, because there are no sensitizer molecules in the film. Therefore, there will not be produced a photocurrent, except the photocurrent generated by PCBM itself. The characteristics of the $J_{\mathrm{SC}}$ and PCE are in a good agreement with that of EQE shown in Figure 4.

\section{Conclusions}

We have constructed the C6:PCBM BHJ solar cells and studied the effect of PCBM concentration on the photocurrent and performance of the solar cells. Although the blend solutions had low concentration $(20 \mathrm{mg} / \mathrm{mL})$, the C6 dye in the active layer blend showed an eminent absorption peak. The absorption of the C6 increased with increasing its concentration in the blends. The C6:PCBM combination showed efficiently exciton dissociation and photocurrent generation as a result of formation of $\mathrm{BHJ}$ between $\mathrm{C} 6$ dye and PCBM. The formation of BHJ was indicated though the matching between EQE and light absorption spectra (symbatic) of the solar cell active layer and, also, through the homogeneity of C6 and PCBM domains in the blend film as shown by AFM images. With the variation in the blending ratio, we found that the increase in PCBM concentration up to $60 \%$ in the solar cell active layer increased the photocurrent up to $12.39 \%$. In addition, the solar cell performance parameters improved with increasing PCBM concentration in the blends. The improvement in the photocurrent and solar cell performance with increasing PCBM concentration in the blends may be attributed to the following:

(1) the increase in the photoactive p-n heterojunction sites and, therefore, charge separation,

(2) the increase in the electron transport throughout percolated pathways produced in the solar cell active layer.

The active layer composition with $60 \%$ of PCBM attained $0.26 \mathrm{~V}$ of $V_{\mathrm{OC}}, 0.36$ of $\mathrm{FF}, 1.1 \mathrm{~mA} / \mathrm{cm}^{2}$ of $J_{\mathrm{SC}}$, and $0.1 \%$ of PCE.

\section{Acknowledgment}

Y. A. M. Ismail acknowledges the Egyptian people and government for supporting this work.

\section{References}

[1] C. Powell, T. Bender, and Y. Lawryshyn, "A model to determine financial indicators for organic solar cells," Solar Energy, vol. 83, no. 11, pp. 1977-1984, 2009.

[2] C. Lungenschmied, G. Dennler, H. Neugebauer et al., "Flexible, long-lived, large-area, organic solar cells," Solar Energy Materials and Solar Cells, vol. 91, no. 5, pp. 379-384, 2007.

[3] H. Y. Chen, J. Hou, S. Zhang et al., "Polymer solar cells with enhanced open-circuit voltage and efficiency," Nature Photonics, vol. 3, no. 11, pp. 649-653, 2009.

[4] X. Jiang, W. F. Burgoyne Jr., and L. M. Robeson, "Sequestration of electroactive materials in a high $\mathrm{Tg}$, insulating polymer matrix for optoelectronic applications. Part 2. Photovoltaic devices," Polymer, vol. 47, no. 11, pp. 4124-4131, 2006.

[5] K. Hara, T. Sato, R. Katoh et al., "Molecular design of coumarin dyes for efficient dye-sensitized solar cells," Journal of Physical Chemistry B, vol. 107, no. 2, pp. 597-606, 2003.

[6] K. Hara, M. Kurashige, Y. Dan-Oh et al., "Design of new coumarin dyes having thiophene moieties for highly efficient organic-dye-sensitized solar cells," New Journal of Chemistry, vol. 27, no. 5, pp. 783-785, 2003.

[7] S. Hao, J. Wu, Y. Huang, and J. Lin, "Natural dyes as photosensitizers for dye-sensitized solar cell," Solar Energy, vol. 80, no. 2, pp. 209-216, 2006.

[8] E. Yamazaki, M. Murayama, N. Nishikawa, N. Hashimoto, M. Shoyama, and O. Kurita, "Utilization of natural carotenoids as photosensitizers for dye-sensitized solar cells," Solar Energy, vol. 81, no. 4, pp. 512-516, 2007. 
[9] A. Montali, A. R. A. Palmans, J. Bras et al., "Depolarizing energy transfer in photoluminescent polymer blends," Synthetic Metals, vol. 115, no. 1, pp. 41-45, 2000.

[10] Y. Takahashi, A. Maeda, K. Kojima, and K. Uchida, "Luminescence of dyes doped in a sol-gel coating film," Journal of Luminescence, vol. 87-89, pp. 767-769, 2000.

[11] A. F. Mansour, H. M. A. Killa, S. A. El-Wanees, and M. Y. El-Sayed, "Laser dyes doped with poly(ST-Co-MMA) as fluorescent solar collectors and their field performance," Polymer Testing, vol. 24, no. 4, pp. 519-525, 2005.

[12] A. F. Mansour, "Photostability and optical parameters of copolymer styrene/MMA as a matrix for the dyes used in fluorescent solar collectors," Polymer Testing, vol. 23, no. 3, pp. 247-252, 2004.

[13] V. Kandavelu, H. S. Huang, J. L. Jian, T. C. K. Yang, K. L. Wang, and S. T. Huang, "Novel iminocoumarin dyes as photosensitizers for dye-sensitized solar cell," Solar Energy, vol. 83, no. 4, pp. 574-581, 2009.

[14] M. J. Brites, C. Santos, S. Nascimento, B. Gigante, and M. N. Berberan-Santos, "Synthesis of [60]fullerene-coumarin polyads," Tetrahedron Letters, vol. 45, no. 37, pp. 6927-6930, 2004.

[15] T. Yamanari, T. Taima, J. Sakai, and K. Saito, "Origin of the open-circuit voltage of organic thin-film solar cells based on conjugated polymers," Solar Energy Materials and Solar Cells, vol. 93, no. 6-7, pp. 759-761, 2009.

[16] C. C. Wu, J. C. Sturm, R. A. Register, J. Tian, E. P. Dana, and M. E. Thompson, "Efficient organic electroluminescent devices using single-layer doped polymer thin films with bipolar carrier transport abilities," IEEE Transactions on Electron Devices, vol. 44, no. 8, pp. 1269-1281, 1997.

[17] J. Nakamura, K. Murata, and K. Takahashi, "Relation between carrier mobility and cell performance in bulk heterojunction solar cells consisting of soluble polythiophene and fullerene derivatives," Applied Physics Letters, vol. 87, no. 13, Article ID 132105, 3 pages, 2005.

[18] A. A. Bakulin, S. G. Elizarov, A. N. Khodarev et al., "Weak charge-transfer complexes based on conjugated polymers for plastic solar cells," Synthetic Metals, vol. 147, no. 1-3, pp. 221$225,2004$.

[19] L. Goris, K. Haenen, M. Nesládek et al., "Absorption phenomena in organic thin films for solar cell applications investigated by photothermal deflection spectroscopy," Journal of Materials Science, vol. 40, no. 6, pp. 1413-1418, 2005.

[20] A. A. Bakulin, D. S. Martyanov, D. Y. Paraschuk, M. S. Pshenichnikov, and P. H. M. van Loosdrecht, "Ultrafast charge photogeneration dynamics in ground-state charge-transfer complexes based on conjugated polymers," Journal of Physical Chemistry B, vol. 112, no. 44, pp. 13730-13737, 2008.

[21] J. K. J. van Duren, X. Yang, J. Loos et al., "Relating the morphology of poly(p-phenylene vinylene)/methanofullerene blends to solar-cell performance," Advanced Functional Materials, vol. 14, no. 5, pp. 425-434, 2004.

[22] C. J. Brabec, S. E. Shaheen, C. Winder, and N. S. Saricifti, "Effect of LiF/metal electrodes on the performance of plastic solar cells," Applied Physics Letters, vol. 80, no. 7, article 1288, 3 pages, 2002.

[23] F. Padinger, R. S. Rittberger, and N. S. Saricifti, "Effects of postproduction treatment on plastic solar cells," Advanced Functional Materials, vol. 13, no. 1, pp. 85-88, 2003.

[24] S. E. Shaheen, C. J. Brabec, N. S. Sariciftci, F. Padinger, T. Fromherz, and J. C. Hummelen, "2.5\% efficient organic plastic solar cells," Applied Physics Letters, vol. 78, no. 6, pp. 841-843, 2001.
[25] J. M. Kroon, M. M. Wienk, W. J. H. Verhees, and J. C. Hummelen, "Accurate efficiency determination and stability studies of conjugated polymer/fullerene solar cells," Thin Solid Films, vol. 403-404, pp. 223-228, 2002.

[26] T. Munters, T. Martens, L. Goris et al., "A comparison between state-of-the-art "gilch" and "sulphinyl" synthesised MDMOPPV/PCBM bulk hetero-junction solar cells," Thin Solid Films, vol. 403-404, pp. 247-251, 2002.

[27] T. Aernouts, W. Geens, J. Poortmans, P. Heremans, S. Borghs, and R. Mertens, "Extraction of bulk and contact components of the series resistance in organic bulk donor-acceptorheterojunctions," Thin Solid Films, vol. 403-404, pp. 297-301, 2002.

[28] T. Aernouts, P. Vanlaeke, W. Geens et al., “The influence of the donor/acceptor ratio on the performance of organic bulk heterojunction solar cells," in Proceedings of the E-MRS Spring Meeting, Strasbourg, France, 2003.

[29] W. Geens, S. E. Shaheen, C. J. Brabec, J. Poortmans, and N. S. Sariciftci, "Field-effect mobility measurements of conjugated polymer/fullerene photovoltaic blends," in 14th International Winterschool/Euroconference, vol. 544 of AIP Conference Proceedings, pp. 516-520, Kirchberg, Austria, 2000.

[30] H. Hoppe and N. S. Sariciftci, "Organic solar cells: an overview," Journal of Materials Research, vol. 19, no. 7, pp. 19241945, 2004.

[31] H. Hoppe and N. S. Sariciftci, "Morphology of polymer/ fullerene bulk heterojunction solar cells," Journal of Materials Chemistry, vol. 16, no. 1, pp. 45-61, 2006.

[32] N. M. Kronenberg, M. Deppisch, F. Würthner, H. W. A. Lademann, K. Deing, and K. Meerholz, "Bulk heterojunction organic solar cells based on merocyanine colorants," Chemical Communications, no. 48, pp. 6489-6491, 2008.

[33] P. Schilinsky, C. Waldauf, J. Hauch, and C. J. Brabec, "Simulation of light intensity dependent current characteristics of polymer solar cells," Journal of Applied Physics, vol. 95, no. 5, pp. 2816-2819, 2004.

[34] V. D. Mihailetchi, J. K. J. van Duren, P. W. M. Blom et al., "Electron transport in a methanofullerene," Advanced Functional Materials, vol. 13, no. 1, pp. 43-46, 2003.

[35] W. Geens, T. Martens, J. Poortmans et al., "Modelling the short-circuit current of polymer bulk heterojunction solar cells," Thin Solid Films, vol. 451-452, pp. 498-502, 2004. 

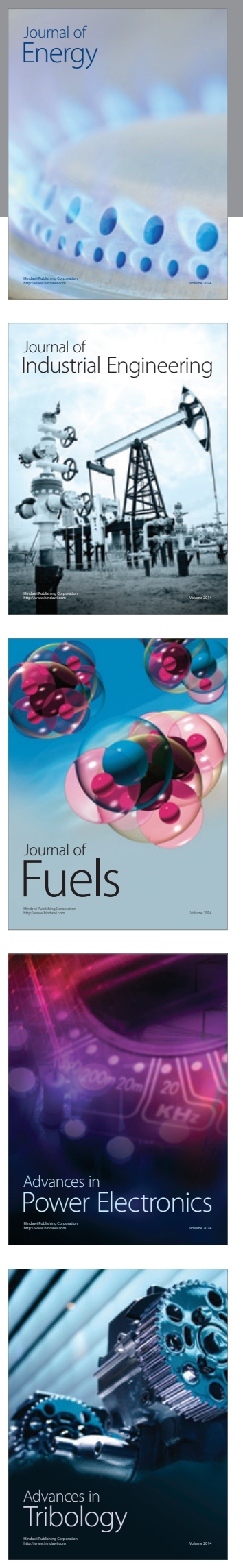
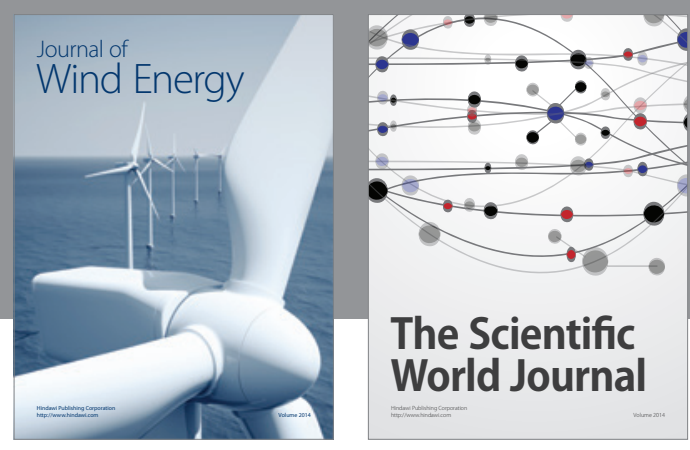

The Scientific World Journal

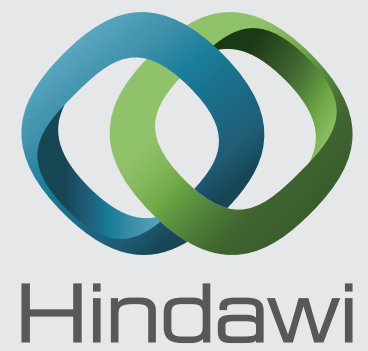

Submit your manuscripts at http://www.hindawi.com
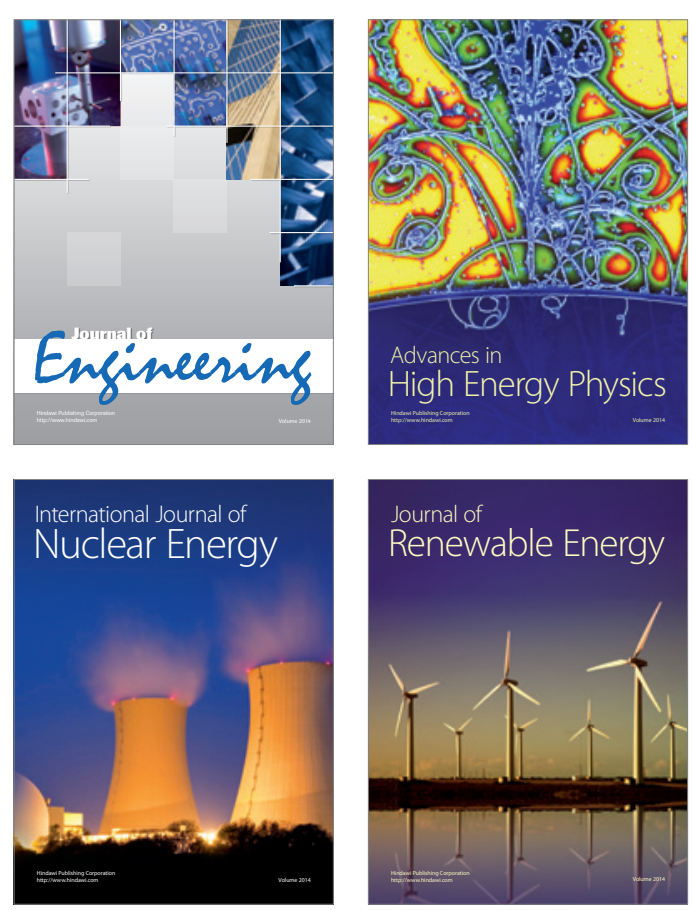

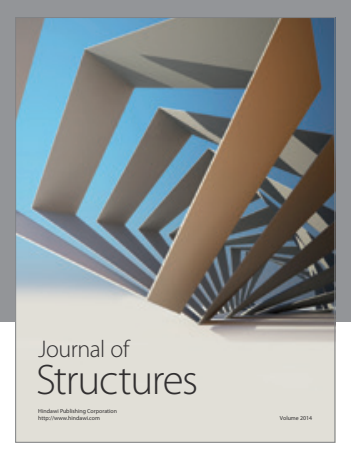

Rotating
Mechinery
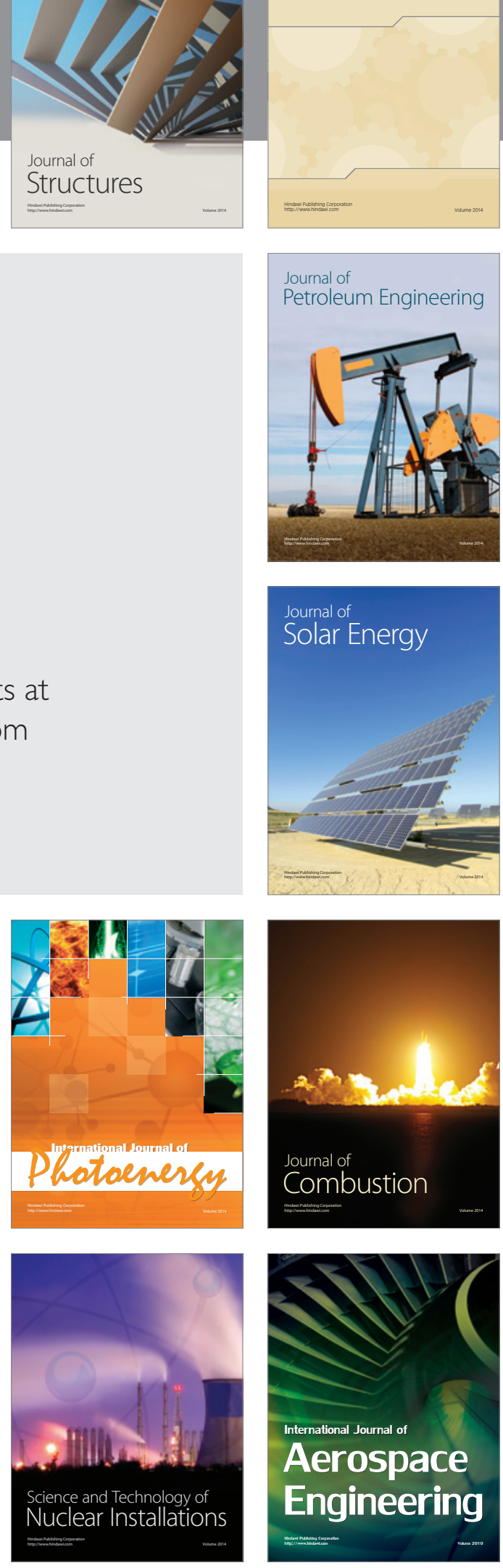